\title{
A Study into the Nature of Emotional Intelligence in Public and Private Institutions in Ghana
}

\section{Chief Bright Akomeah \\ Francis Duah ${ }^{2}$ (D)

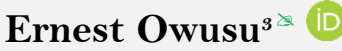

${ }_{1,2, s}$ Sunyani Technical University, Ghana.

Email:akomeah20@yahoo.com Tel: 024236052s

Email:franduah12@gmail.com Tel:0244570918

${ }^{3}$ Email:ramzypapa@yahoo.com Tel:0244826690

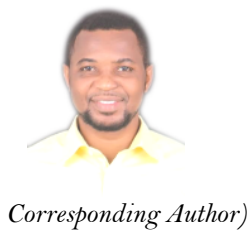

( Corresponding Author)

\begin{abstract}
The purpose of the study is to examine the nature of emotional intelligence in a survey using respondents from both public and private institutions. The study design is quantitative, descriptive, and cross-sectional research. The sample size for the study was 140 sampled using the convenience sample method. The questionnaire for the collection of data was designed by the researchers using the Likert Scale format. The reliability of the scales and the dimensions of the scales were investigated using reliability, and factor analysis tests respectively. The data was analysed using the IBM SPSS Statistics 26. The results show the responses were reliable and the scales were also unidimensional. Various dimensions of emotional intelligence were identified as awareness of own emotions; management of emotions; awareness of others' emotions; and management of others' emotions. Management of institutions should consider in their organisational strategies, the findings of the present research to ensure the efficient running of the institutions. The role of demographic features in emotional intelligence is a recommended direction for future studies.
\end{abstract}

Keywords: Awareness of own emotions, Management of own emotions, Awareness of others' emotions, Management of others' emotions, Emotional intelligence, Public institutions.

JEL Classification: D90, D91.

Citation | Chief Bright Akomeah; Francis Duah; Ernest Owusu (2021). A Study into the Nature of Emotional Intelligence in Public and Private Institutions in Ghana. Asian Journal of Social Sciences and Management Studies, 8(2): 53-60.

History:

Received: 6 April 2021

Revised: 10 May 2021

Accepted: 3 June 2021

Accepted: 3 Jus 2021

Licensed: This work is licensed under a Creative Commons

Attribution 3.0 License (cc)

Publisher: Asian Online Journal Publishing Group
Acknowledgement: All authors contributed to the conception and design of the study.

Funding: This study received no specific financial support

Competing Interests: The authors declare that they have no conflict of interests.

Transparency: The authors confirm that the manuscript is an honest, accurate, and transparent account of the study was reported; that no vital features of the study have been omitted; and that any discrepancies from the features of the study have been omitted;
study as planned have been explained.

Ethical: This study follows all ethical practices during writing.

\section{Contents}

1. Introduction

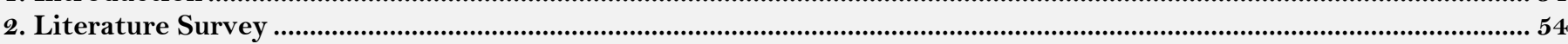

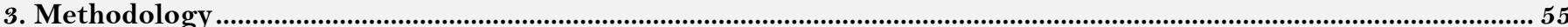

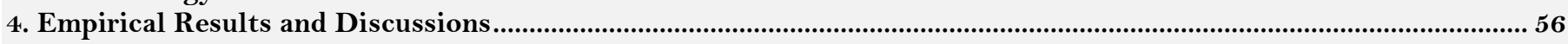

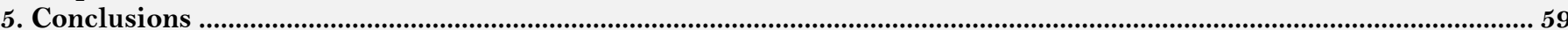

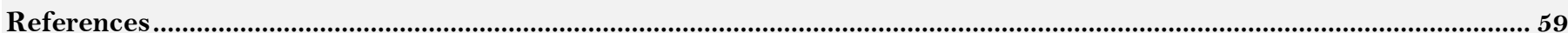




\section{Contribution of this paper to the literature}

The paper contributes to the body of literature in the area of emotional intelligence by examining the nature of emotional intelligence in the current study areas since in the knowledge of the authors no such work exists, and hence the paper fills in this knowledge gap. In the current infrastructure of the institutions, with technology and modern processes of doing things, the present paper investigates whether emotional intelligence among the respondents is high or low. Addressing the gap will afford management of institutions information on the nature of emotional intelligence levels among the employees to appropriately provide the needed human resources programmes that will help them optimize productivity, in the bide to achieve their core goals as management of the institutions.

\section{Introduction}

Research in the area of emotional intelligence (EI) continues to attract attention in the literature ever since the formal treatment of the subject in terms of theory by Mayer and Salovey (1990) after previous empirical works. This sustained interest stem from the fact that emotional intelligence impact significantly on all known cultures and academic communities. These research works have taken the form of academic debate in the field of management and psychology, among researchers and practitioners, intending to understand the concepts of emotional intelligence and how to put into use the principles of emotional intelligence (Emmerling \& Goleman, 2003).

According to researchers (Boyatzis, 1982; Goleman, 1998; Goleman, 2001; Goleman, Boyatzis, \& McKee, 2002; Schmidt \& Hunter, 1981; Spencer \& Spencer, 1993; Sternberg, 1997), empirical research in emotional intelligence is currently still relevant since EI is very important in predicting worker performance, job satisfaction, motivation and many issues, even higher than that of the traditional measures of intelligence, such as the intelligence quotient.

In the literature (Gardner, 2013; Mayer \& Salovey, 1990; Mayer, Caruso, \& Salovey, 1999; Steiner, 1984) emotion is explained as an individual potential to be able to manage personal emotions and feelings, and other persons also emotions and feelings. It is further considered as an individual capacity to be able to recognise and bring out emotions to be able to aid judgement. Emotional intelligence is considered to vary from individual to individual and that an individual deals with emotional issues differently. Hence, peoples use different adaptive strategies to deal with emotional issues (George, 2000; Mayer \& Salovey, 1990).

The literature (Mayer \& Salovey, 1990; Wasielewski, 1985) indicates that individuals with higher levels of emotional intelligence are more productive on various tasks as compared with individuals that have lower emotional intelligence, and they are also good leaders. Higher levels of emotional intelligence in addition help individuals to be able to deal with other person feelings and emotions appropriately when socialising.

The current research is necessitated by the fact that empirical research findings (Cote \& Miners, 2006; Law, Wong, \& Song, 2004; Van Rooy \& Viswesvaran, 2004) conclude that workers higher on emotional intelligence are more productive at the job place than workers with lower emotions and feelings, who are considered as less productive, and poor leaders with weak planning skills.

The nature of emotional intelligence has not been examined in the current study areas in the knowledge of the authors, and hence the paper fills in this knowledge gap to add to the existing literature. In the current infrastructure of the institutions, with technology and modern processes of doing things, the present paper investigates whether emotional intelligence among the respondents is high or low. Addressing the gap will afford management of institutions information on the nature of emotional intelligence levels among the employees to appropriately provide the needed human resources programmes that will help them optimize productivity, in the bide to achieve their core goals as management of the institutions. Respondents will also be aware of their emotional intelligence nature and that will help them to take achieve decisions in improving their emotional levels if they happen to have low emotional levels. Knowledge of the respondent's emotional level will help respondents to be able to predict their work behaviour and the other demands of their job. It will also help to determine whether respondents in the survey are emotionally stable or not.

The research is based on a global objective of investigating the nature of emotional intelligence among the employees and the ranks of the emotional intelligence among the respondents. The particular intentions of the present study are to assess the sorts of emotional intelligence among the respondents and to rank the identified emotional levels of the respondents.

The research is underpinned by the following question: What are the sorts of emotional intelligence among the respondents in the survey? What are the ranks of the emotional intelligence identified? The propositions for the paper are; there are higher levels of emotional intelligence among respondents in the study and that, some emotional constructs are highly ranked than others by the respondents.

The research delimitations are that some respondents might have been economical with information when responding to the items in the questionnaire. There could be under-reporting or over-reporting of responses by respondents. Causality issues were also not examined in the study. The sample is based on a non-probability sample method and as such, the findings may lack external validity. The study did not consider the effect of emotional intelligence on other dimensions of an individual employee, and work environments such as job performance, motivation, satisfaction, and adaptive strategies of emotional intelligence.

The rest of the manuscript looks at the literature survey (section 2); methodology (section 3); results and discussions (section 4); and conclusions (section 5).

\section{Literature Survey}

There have been Prior research efforts to examine and measure the nature of emotional intelligence empirically in various institutions both private and public. The findings are found in the works of various researchers (Asrarul-Haq, Anwar, \& Hassan, 2017; Befort \& Hattrup, 2003; Bono, Foldes, Vinson, \& Muros, 2007; Bono \& Vey, 2007; Brotheridge, 2006; Carmeli, 2003; Day \& Carroll, 2004; Diefendorff, Croyle, \& Gosserand, 2005; Fox \& Spector, 2000; Grandey, Fisk, \& Steiner, 2005; Joseph \& Newman, 2010; Kellett, Humphrey, \& Sleeth, 2006; Mayer \& Cobb, 2000; Mayer, Salovey, Caruso, \& Sitarenios, 2001; Murphy, 1989; Offermann, Bailey, Vasilopoulos, Seal, \& Sass, 2004; Pugh, 2001; Sy, Tram, \& O'hara, 2006). 
Fox and Spector (2000) in a survey identified various emotional intelligence measures and their effect on worker performance and reported that respondents have different levels of emotional intelligence, such as high and low levels. Mayer and Cobb (2000) in their study examined the various construct of emotional intelligence among respondents and reported that emotional intelligence is associated positively with respondents work effort.

Mayer et al. (2001) reported that respondents have different levels of emotions and that those with higher emotional levels have a good work relationship with co-workers than those with low emotional intelligence levels.

In the empirical study of Befort and Hattrup (2003), they pointed out various emotional measures among the respondents and indicated that respondents with higher emotional intelligence can manage effectively their psychological state of mind and also are more productive at the job place than respondents lower on the emotional intelligence scale.

Day and Carroll (2004) investigated different constructs of emotional intelligence, and reported various dimensions of emotional intelligence among the respondents and concluded that they are associated with worker performance. They indicated that there is a need to improve the emotional performance of employees to enhance worker work effort. Offermann et al. (2004) studied the emotional profiles of respondents and reported that respondents exhibit various aspects of emotional intelligence and concluded that worker performance in teamwork is associated with emotional intelligence.

In the study by Kellett et al. (2006) on the role of emotional intelligence in leadership, they recognized various emotional intelligence measures and concluded that the identified emotional intelligence measures predict the surfacing of leaders in a group. Sy et al. (2006) in a study of leadership and emotional intelligence recognised different aspects of emotional intelligence among the respondents and stated that emotional intelligence is associated with the performance of leaders. Their findings are also in support of that of Bono et al. (2007) study on emotional intelligence and leadership. Bono et al. (2007) also concluded that leaders high in emotional intelligence are more stable in their temperament when dealing with co-workers. They also identified various aspect of emotional intelligence with various levels.

Dunaway (2013) explored the dimensions of emotional intelligence and reported various dimensions of emotional intelligence such as awareness of own emotions; management of own emotions; awareness of others' emotions; and management of others 'emotions. They concluded that awareness and management of one's own emotion significantly affect team effectiveness.

Ugoani, Amu, and Kalu (2015) investigated emotional intelligence and how it affects leadership. Their study findings indicated self-awareness, self-confidence, emotional management, empathy, and transparency are emotional intelligence domains among the respondents and they affect leadership performance.

Masa'deh (2016) in Jordan investigated the nature of emotional intelligence and the effect it has on organisational effectiveness. The study reported various dimensions of emotional intelligence such as management of other's emotion; awareness of other's emotions; management of one's own emotion; and awareness of one's own emotion.

In Pakistan, Asrar-ul-Haq et al. (2017) examined the effect of emotional intelligence on worker performance and identified various constructs of emotional intelligence such as conflict management, developing other colleagues, achievement, self-confidence, emotional self-awareness, and self-confidence.

\section{Methodology}

\subsection{Research Design/Strategy/Type}

The quantitative research design employed in the present research, to quantify the responses on the nature of emotional intelligence in the study area. The research is also a descriptive study in which the domains of emotional intelligence as exist in the study area are described. In addition, the study is not longitudinal but cross-sectional research and as such data is taken from the respondents once and analysed.

\subsection{Research Population/Sample size/Sampling Method}

The target population for the study is the staff of the public and private institutions in Sunyani municipality. A sample size of 140 respondents was used. Table 1 in section 4 shows the respondents biographical information. The sample size for the study was selected using the convenience sampling method. In this method of sample, a respondent is included for the reason that the respondent is easily accessible to the researchers.

\subsection{Data collection Instruments}

The research questionnaire in the format of the five-point (5-point) Likert scale (Strongly Agreed, Agreed, Neutral, disagree, strongly disagree), and codes were designed by the researcher, using information from the prior research effort surveyed in section 2 of the current paper. The working hours of the respondents were used to administer the questionnaire. The items on the questionnaire were closed-ended. Hence, respondents only ticked the responses as applied to them.

\subsection{Data Analysis and Presentation of Empirical Results}

Data collected were analysed using descriptive statistics such as frequencies, percentages, mean, and standard deviation of responses. The reliability test was also performed to assess the reliability of the responses provided by the respondents. The results are presented in Tables in section 4 of the paper.

\subsection{Conceptual Framework}

Figure 1 depicts the conceptual framework for the current research. The model considers emotional intelligence as consisting of various domains which are indicated in figure 1. Various models in the literature are used to measure the domains of emotional intelligence (Ugoani et al., 2015). These models are found in the works of various authors (Bar-On, 1997; Goleman, 2001; Mayer \& Salovey, 1997; Petrides, Pita, \& Kokkinaki, 2007). The models are Mayer, Salovey, and Caruso (2002) (MSCEIT); Interpersonal EQ, Adaptability EQ, Stress management EQ, Impulse Control EQ, and General mood EQ; Emotional Competency Inventory (ECI); The Trait Emotional 
Intelligence Questionnaire (TEIQue). The current model has based on the works of these authors (Goleman, 1995). Goleman (1995) identified five subdomains (Know your emotions; Manage your emotions; Motivate yourself; Recognise and understand other people's emotions; manage relationships (other people's emotions)) of emotional intelligence from the main four domains and stated that emotional intelligence consists of (1) Self-Awareness; (2) Self-Management; (3) Social Awareness; and (Relationship Management).

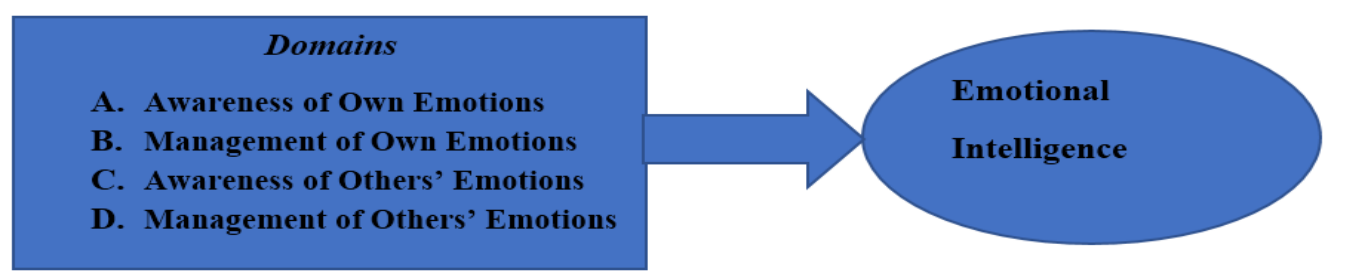

Figure-1. A conceptual framework for the explanation of emotional intelligence domain.

\section{Empirical Results and Discussions}

4.1. Background Information on Respondents

Table 1 indicates the demographic features of the respondents in the study. The results show that the majority $(57.9 \%)$ of the respondents were males; a majority (39.3\%) belong to the age group of 30-39 years; a majority $(62.1 \%)$ hold undergraduate certificate; a majority (50.7\%) are married; most (43.6\%) are senior members; most $(32.9 \%)$ have worked between 3-5years; a majority (69.3\%) were Christians; and lastly, a majority (57.9\%) of the respondents were from Brong Ahafo.

Table-1. Demographic profile of respondents.

\begin{tabular}{|c|c|c|}
\hline Variables & Frequency & Percentage (\%) \\
\hline \multicolumn{3}{|l|}{ Gender } \\
\hline Male & 81 & 57.9 \\
\hline Female & 59 & 42.1 \\
\hline Total & 140 & 100.0 \\
\hline \multicolumn{3}{|l|}{ Age } \\
\hline $20-29$ & 37 & 26.4 \\
\hline $30-39$ & 55 & 39.3 \\
\hline $40-49$ & 38 & 27.1 \\
\hline $50-59$ & 10 & 7.1 \\
\hline Total & 140 & 100.0 \\
\hline \multicolumn{3}{|l|}{ Educational status } \\
\hline First Degree/HND/Diploma & 87 & 62.1 \\
\hline Masters & 41 & 29.3 \\
\hline PhD & 12 & 8.6 \\
\hline Total & 140 & 100.0 \\
\hline \multicolumn{3}{|l|}{ Marital status } \\
\hline Single & 62 & 44.3 \\
\hline Married & 71 & 50.7 \\
\hline Divorced & 7 & 5.0 \\
\hline Total & 140 & 100.0 \\
\hline \multicolumn{3}{|l|}{ Current work status } \\
\hline Junior staff & 48 & 34.3 \\
\hline Senior staff & 61 & 43.6 \\
\hline Senior member & 30 & 21.4 \\
\hline Missing response & 1 & 0.7 \\
\hline Total & 140 & 100.0 \\
\hline \multicolumn{3}{|c|}{ Length of service in the current position } \\
\hline 2years and less & 40 & 28.6 \\
\hline 3-5years & 46 & 32.9 \\
\hline 6-8years & 26 & 18.6 \\
\hline 9years and above & 28 & 20.0 \\
\hline Total & 140 & 100.0 \\
\hline \multicolumn{3}{|l|}{ Religion (Belief) } \\
\hline Christian & 97 & 69.3 \\
\hline Muslim & 30 & 21.4 \\
\hline Traditional & 6 & 4.3 \\
\hline Other religion & 7 & 5.0 \\
\hline Total & 140 & 100.0 \\
\hline \multicolumn{3}{|l|}{ Region (Culture) } \\
\hline Upper West & 12 & 8.6 \\
\hline Upper East & 9 & 6.4 \\
\hline Northern & 10 & 7.1 \\
\hline Brong Ahafo & 81 & 57.9 \\
\hline Ashanti & 6 & 4.3 \\
\hline Western & 7 & 5.0 \\
\hline Eastern & 4 & 2.9 \\
\hline Central & 7 & 5.0 \\
\hline Greater & 1 & 0.7 \\
\hline Volta & 3 & 2.1 \\
\hline Total & 140 & 100.0 \\
\hline
\end{tabular}




\subsection{Results of Reliability Test}

The results of reliability test for the dimensions of emotional intelligence are shown in Table 2 (All the domains of emotional intelligence analysed together), and Table 3 (when the domains are separated into four) The results show high internal consistency since the value of the Cronbach alpha coefficients is all above 0.7. This means the questionnaire used to collect data is adequate and reliable as Cronbach (1951) explained.

Table-2. Results of Reliability analysis for Emotional Intelligence dimensions.

\begin{tabular}{c|c|c|c}
\hline Categories of Statements & Cronbach's alpha & No. of Items & Conclusion \\
\hline Emotional intelligence domains & 0.860 & 15 & High reliability \\
\hline
\end{tabular}

Table-3. Results of Reliability analysis for Emotional Intelligence dimensions.

\begin{tabular}{l|c|c|l}
\hline $\begin{array}{l}\text { Categories of Statements } \\
\text { Emotional Intelligence Domains }\end{array}$ & Cronbach's alpha & No. of Items & Conclusion \\
\hline Awareness of own emotions & 0.901 & 4 & Very high reliability \\
\hline Management of own emotions & 0.771 & 4 & High reliability \\
\hline Awareness of others' emotions & 0.818 & 3 & High reliability \\
\hline Management of others 'emotions & 0.854 & 4 & High reliability \\
\hline
\end{tabular}

\subsection{Test for Dimensionality of the Key Domains of Emotional Intelligence Used in the Study}

After testing for the reliability of the set of items used, the set of items were statistically examined to determine if they measure just one common thing (Emotional Intelligence), using the dimensionality test. The results are shown in Table 4 to Table 7 . The test results in all the Tables indicate uni-dimensionality of the scales, since in all the test results as shown in the Tables, only the first component is larger and also explains the variance in the components using the initial Eigenvalues. In Table 4, the first component explains about $77 \%$; in Table 5 , about $60 \%$; in Table 6 , about $73 \%$; in Table 7 , about $70 \%$, in the variance.

Table-4. Test results for dimensionality.

\begin{tabular}{|c|c|c|c|c|c|c|}
\hline \multicolumn{4}{|c|}{ Initial Eigenvalues } & \multicolumn{3}{|c|}{ Extraction Sums of Squared Loadings } \\
\hline Components & Totals & $\%$ of Variance & Cumulative \% & Total & \% of Variance & Cumulative \% \\
\hline 1 & 3.096 & 77.402 & 77.402 & 3.096 & 77.402 & 77.402 \\
\hline 2 & 0.496 & 12.399 & 89.800 & & & \\
\hline 3 & 0.232 & 5.789 & 95.589 & & & \\
\hline 4 & 0.176 & 4.411 & 100.000 & & & \\
\hline
\end{tabular}

Table-5. Test results for dimensionality.

\begin{tabular}{|c|c|c|c|c|c|c|}
\hline \multicolumn{4}{|c|}{ Initial Eigenvalues } & \multicolumn{3}{|c|}{ Extraction Sums of Squared Loadings } \\
\hline Components & Totals & $\%$ of Variance & Cumulative \% & Total & \% of Variance & Cumulative \% \\
\hline 1 & 2.403 & 60.070 & 60.070 & 2.403 & 60.070 & 60.070 \\
\hline 2 & 0.736 & 18.408 & 78.477 & & & \\
\hline 3 & 0.538 & 13.445 & 91.922 & & & \\
\hline 4 & 0.323 & 8.078 & 100.000 & & & \\
\hline
\end{tabular}

Table-6. Test results for dimensionality.

\begin{tabular}{c|c|c|c|c|c|c}
\hline \multicolumn{5}{c}{ Initial Eigenvalues } & \multicolumn{3}{c}{ Extraction Sums of Squared Loadings } \\
\hline Components & Totals & \% of Variance & Cumulative \% & Total & \% of Variance & Cumulative \% \\
\hline 1 & 2.201 & 73.365 & 73.365 & 2.201 & 73.365 & 73.365 \\
\hline 2 & 0.510 & 17.011 & 90.376 & & & \\
\hline 3 & 0.289 & 9.624 & 100.000 & & & \\
\hline
\end{tabular}

Table-7. Test Results for dimensionality.

\begin{tabular}{c|c|c|c|c|c|c}
\hline \multicolumn{5}{c}{ Initial Eigenvalues } & \multicolumn{2}{c}{ Extraction Sums of Squared Loadings } \\
\hline Components & Totals & \% of Variance & Cumulative \% & Total & \% of Variance & Cumulative \% \\
\hline 1 & 2.793 & 69.816 & 69.816 & 2.793 & 69.816 & 69.816 \\
\hline 2 & 0.576 & 14.391 & 84.207 & & & \\
\cline { 1 - 4 } 3 & 0.381 & 9.513 & 93.720 & & \\
\hline 4 & 0.251 & 6.280 & 100.000 & & \\
\hline
\end{tabular}

\subsection{Normality Test}

The Kolmogorov-Smirnova and Shapiro-Wilk tests were performed to explore the nature of normality of the data set. Table 8 report the test results. The results in Table 8 indicate the data set are not normally distributed, since the P-values of the tests are less than 0.05. This indicates the data significantly deviate from a normal distribution.

\subsection{Analysis of Emotional Intelligence Domains}

Table 9 shows the values of the standard deviations and the score of means for each emotional intelligence key domains. In all, four (4) domains were identified in the research. They are awareness of own emotions; management of own emotions; awareness of others' emotions; and management of others' emotions. Each domain has subdimensions as a measure of the key domain. 
Table-8. Normality Test Results

\begin{tabular}{|c|c|c|c|c|c|c|}
\hline \multirow[t]{2}{*}{ Scales } & \multicolumn{3}{|c|}{ Kolmogorov-Smirnova } & \multicolumn{3}{|c|}{ Shapiro-Wilk } \\
\hline & Statistic & df & P-Values & Statistic & df & P-Values \\
\hline I can explain the emotions I feel to my colleagues. & 0.290 & 140 & 0.000 & 0.799 & 140 & 0.000 \\
\hline I can discuss the emotions I feel with other colleagues. & 0.292 & 140 & 0.000 & 0.834 & 140 & 0.000 \\
\hline $\begin{array}{l}\text { If I feel down, I can tell my colleagues what will make me } \\
\text { feel better. }\end{array}$ & 0.251 & 140 & 0.000 & 0.846 & 140 & 0.000 \\
\hline $\begin{array}{l}\text { I can talk to other colleagues about the emotions I } \\
\text { experience }\end{array}$ & 0.286 & 140 & 0.000 & 0.845 & 140 & 0.000 \\
\hline $\begin{array}{l}\text { I respect the opinion of my colleagues, even if I think they } \\
\text { are wrong. }\end{array}$ & 0.267 & 140 & 0.000 & 0.859 & 140 & 0.000 \\
\hline $\begin{array}{l}\text { When I am frustrated with my colleagues, I can overcome } \\
\text { my frustration. }\end{array}$ & 0.242 & 140 & 0.000 & 0.832 & 140 & 0.000 \\
\hline $\begin{array}{l}\text { When deciding on a dispute, I try to see all sides of a } \\
\text { disagreement before I conclude. }\end{array}$ & 0.289 & 140 & 0.000 & 0.820 & 140 & 0.000 \\
\hline I give a fair hearing to my colleagues' ideas & 0.289 & 140 & 0.000 & 0.825 & 140 & 0.000 \\
\hline $\begin{array}{l}\text { I can read my colleagues "true" feelings, even if they try to } \\
\text { hide them. }\end{array}$ & 0.228 & 140 & 0.000 & 0.882 & 140 & 0.000 \\
\hline $\begin{array}{l}\text { When I talk to my colleagues, I can gauge their true } \\
\text { feelings from their body language. }\end{array}$ & 0.245 & 140 & 0.000 & 0.867 & 140 & 0.000 \\
\hline I can tell when my colleagues don't mean what they say. & 0.270 & 140 & 0.000 & 0.865 & 140 & 0.000 \\
\hline My enthusiasm can be contagious for my colleagues. & 0.266 & 140 & 0.000 & 0.862 & 140 & 0.000 \\
\hline $\begin{array}{l}\text { I am able to cheer my colleagues up when they are feeling } \\
\text { down. }\end{array}$ & 0.309 & 140 & 0.000 & 0.815 & 140 & 0.000 \\
\hline I can get my colleagues to share my keenness for a project. & 0.307 & 140 & 0.000 & 0.828 & 140 & 0.000 \\
\hline I can provide the "spark" to get my colleagues enthusiastic. & 0.257 & 140 & 0.000 & 0.850 & 140 & 0.000 \\
\hline
\end{tabular}

The subdimensions have been ranked. The two most ranked dimensions of each key domain as indicated in Table 8 are as follows: For the awareness of own emotions domain, they are 'I can explain the emotions I feel to my colleagues', and 'If I feel down, I can tell my colleagues what will make me feel better, respectively. In the case, of management of own emotions, they are 'when I am frustrated with my colleagues, I can overcome my frustration', and 'when deciding on a dispute, I try to see all sides of a disagreement before I conclude', respectively. The first two most ranked dimensions for awareness of others emotions are 'when I talk to my colleagues, I can gauge their "true" feelings from their body language, and 'I can read my colleagues "true" feelings, even if they try to hide them', respectively. Lastly, for the management of others' emotions, the first two most ranked dimensions are 'I can provide the "spark" to get my colleagues enthusiastic', and 'I can cheer my colleagues up when they are feeling down, respectively.

Table-9. Results on the dimensions of emotional intelligence.

\begin{tabular}{|c|c|c|c|c|}
\hline Dimensions of Emotional Intelligence & $\mathbf{N}$ & Mean & $\begin{array}{l}\text { Standard } \\
\text { deviation }\end{array}$ & Ranks \\
\hline \multicolumn{5}{|l|}{ Awareness of own emotions } \\
\hline i. I can explain the emotions I feel to my colleagues. & 140 & 3.9286 & 1.1165 & 1 \\
\hline ii. I can discuss the emotions I feel with other colleagues. & 140 & 3.8357 & 1.0361 & 3 \\
\hline iii. If I feel down, I can tell my colleagues what will make me feel better. & 140 & 3.8857 & 1.0394 & 2 \\
\hline iv. I can talk to other colleagues about the emotions I experience. & 140 & 3.8286 & 0.9441 & 4 \\
\hline \multicolumn{5}{|l|}{ Management of own emotions } \\
\hline i. I respect the opinion of my colleagues, even if I think they are wrong. & 140 & 3.8571 & 0.9412 & 4 \\
\hline ii. When I am frustrated with my colleagues, I can overcome my frustration. & 140 & 4.0500 & 0.8841 & 1 \\
\hline $\begin{array}{l}\text { iii. When deciding on a dispute, I try to see all sides of a disagreement before I } \\
\text { conclude. }\end{array}$ & 140 & 4.0071 & 0.8439 & 2 \\
\hline iv. I give a fair hearing to my colleagues' ideas. & 140 & 3.9929 & 0.8936 & 3 \\
\hline \multicolumn{5}{|l|}{ Awareness of others' emotions } \\
\hline i. I can read my colleagues "true" feelings, even if they try to hide them. & 140 & 3.7214 & 1.0254 & 2 \\
\hline $\begin{array}{l}\text { ii. When I talk to my colleagues, I can gauge their true feelings from their body } \\
\text { language. }\end{array}$ & 140 & 3.7214 & 1.0733 & 1 \\
\hline iii. I can tell when my colleagues don't mean what they say. & 140 & 3.6714 & 1.0139 & 3 \\
\hline \multicolumn{5}{|l|}{ Management of others 'emotions } \\
\hline i. My enthusiasm can be contagious for my colleagues. & 140 & 3.7000 & 0.9574 & 4 \\
\hline ii. I am able to cheer my colleagues up when they are feeling down. & 140 & 3.8786 & 0.9404 & 2 \\
\hline iii. I can get my colleagues to share my keenness/Zeal for a project. & 140 & 3.7929 & 0.8855 & 3 \\
\hline iv. I can provide the "spark" to get my colleagues enthusiastic. & 140 & 3.9000 & 0.9237 & 1 \\
\hline
\end{tabular}

\subsection{Discussions}

The research used both public and private institutional-based cross-sectional research to investigate the nature of the key emotional intelligence domains in Sunyani Township. The research findings show four key emotional intelligence domains in the study. They are awareness of own emotions; management of own emotions; awareness of other's emotions; and the management of other's emotions.

The research findings are in line with that of prior research efforts that explored the nature of emotional intelligence such as Dunaway (2013) who explored the dimensions of emotional intelligence and reported various dimensions such as awareness of own emotions; management of own emotions; awareness of others' emotions; and management of others 'emotions; Ugoani et al. (2015) who investigated the emotional intelligence dimensions and indicated self-awareness, self-confidence, emotional management, empathy, and transparency as the main domains 
among the respondents; Masa'deh (2016) who examined the nature of emotional intelligence and reported of various dimensions such as management of other's emotion; awareness of other's emotions; management of one's own emotion; and awareness of one's own emotion. In a similar study, Asrar-ul-Haq et al. (2017) identified conflict management, developing other colleagues, achievement, self-confidence, emotional self-awareness, and selfconfidence as the key dimensions of emotional intelligence. The findings imply that respondents in the study do not have a problem with the issues of emotional intelligence and as such other aspects of the organisations might not suffer negatively since they score higher on the scale used to measure the nature of emotional intelligence. Emotional intelligence is and continues to be important in any organisation, and worker must be encouraged to learn skills that will aid them to improve on these emotional intelligence dimensions.

\section{Conclusions}

The purpose of the study has been achieved by examining the nature of emotional intelligence in a survey using respondents from both public and private institutions. The reliability of the scales and the dimensions of the scales (whether unidimensional and multidimensional) were investigated using reliability test (Cronbach Alpha), and factor analysis (Principal Component Analysis) respectively. The results show the responses were reliable and the scales were also unidimensional. Various dimensions of emotional intelligence and their subdimensions were identified as awareness of own emotions; management of emotions; awareness of others' emotions; and management of others' emotions. The various subdimensions of emotional intelligence are differently ranked among respondents.

Management of institutions should consider in their organisational strategies, the findings of the present research to ensure the efficient running of the institutions. Various policies should be put in place to help employees to learn to improve on their emotions and feelings so that the organisations will benefit from employees' high emotions and feelings. The findings support the theories on the dimensions of emotional intelligence among employees. The theories indicate workers possess various emotional intelligence at very levels of high and low, and that these levels can be enhanced through learning.

Further empirical studies, considering comparative analysis involving private and public universities are worth embarking on. The role of demographic features in emotional intelligence is also a good line of research in future studies. Studies on the effect of emotional intelligence on motivation, job satisfaction, and job performance are in addition worth doing in the current study area. Causal studies using the structural modelling method on the effect of emotional intelligence on motivation, job satisfaction, and job performance should be considered in subsequent studies.

\section{References}

Asrar-ul-Haq, M., Anwar, S., \& Hassan, M. (2017). Impact of emotional intelligence on teacher' s performance in higher education institutions of Pakistan. Future Business Journal, 3(2), 87-97. Available at: https://doi.org/10.1016/j.fbj.2017.05.003.

Bar-On, R. (1997). EQ-i. BarOn emotional quotient inventory. A measure of emotional intelligence. User's manual. Toronto: Multi-Health Systems.

Befort, N., \& Hattrup, K. (2003). Valuing task and contextual performance: Experience, job roles, and ratings of the importance of job behaviors. Applied HRM Research, 8(1), 17-32.

Bono, J. E., Foldes, H. J., Vinson, G., \& Muros, J. P. (2007). Workplace emotions: The role of supervision and leadership. Journal of applied Psychology, 92(5), 1357-1367. Available at: https://doi.org/10.1037/002 1-9010.92.5.1357.

Bono, J. E., \& Vey, M. A. (2007). Personality and emotional performance: Extraversion, neuroticism, and self-monitoring. Journal of Occupational Health Psychology, 12(2), 177-192. Available at: https://doi.org/10.1037/1076-8998.12.2.177.

Boyatzis, R. E. (1982). The competent manager: A model for effective performance. New York: John Wiley \& Sons.

Brotheridge, C. M. (2006). The role of emotional intelligence and other individual difference variables in predicting emotional labor relative to situational demands. Psicothema, 18(1), 139-144.

Carmeli, A. (2003). The relationship between emotional intelligence and work attitudes, behavior and outcomes: An examination among senior managers. Journal of managerial Psychology, 18(8), 788-813.

Cote, S., \& Miners, C. T. (2006). Emotional intelligence, cognitive intelligence, and job performance. Administrative Science Quarterly, 51(1), 128.

Cronbach, L. J. (1951). Coefficient alpha and the internal structure of tests. Psychometrika, 16(3), 297-334.

Day, A. L., \& Carroll, S. A. (2004). Using an ability-based measure of emotional intelligence to predict individual performance, group performance, and group citizenship behaviours. Personality and Individual Differences, 36(6), 1443-1458.

Diefendorff, J. M., Croyle, M. H., \& Gosserand, R. H. (2005). The dimensionality and antecedents of emotional labor strategies. Journal of Vocational Behavior, 66(2), 339-357. Available at: https://doi.org/10.1016/j.jvb.2004.02.001.

Dunaway, M. M. (2013). IS learning: The impact of gender and team emotional intelligence. Journal of Information Systems Education, 24(3), 189-202.

Emmerling, R. J., \& Goleman, D. (2003). Emotional intelligence: Issues and common misunderstandings. Issues in Emotional Intelligence, 1(1), $1-32$.

Fox, S., \& Spector, P. E. (2000). Relations of emotional intelligence, practical intelligence, general intelligence, and trait affectivity with interview outcomes: It's not all just 'G'. Journal of Organizational Behavior: The International Journal of Industrial, Occupational and Organizational Psychology and Behavior, 21(2), 203-220. Available at: https://doi.org/10.1002/(sici)10991379(200003)2 1:2<203::aid-job38>3.0.co;2-z.

Gardner, H. (2013). The theory of multiple intelligences. In A. S. Mayes \& B. Moon (Eds.), Teaching and learning in the secondary school (pp. 38). New York: Routledge.

George, J. M. (2000). Emotions and leadership: The role of emotional intelligence. Human Relations, 53(8), $1027-1055$.

Goleman, D. (1995). Emotional Intelligence. New York: Bantam Books.

Goleman, D. (1998). Working with emotional intelligence. New York: Bantam Books.

Goleman, D. (2001). Emotional intelligence: Issues in paradigm building. In C. Cherniss \& D. Goleman (Eds.), The Emotionally Intelligent Workplace (pp. 13-26). Jossey-Bass: San Francisco.

Goleman, D., Boyatzis, R., \& McKee, A. (2002). Primal leadership. Boston: Harvard Business School Press.

Grandey, A. A., Fisk, G. M., \& Steiner, D. D. (2005). Must" service with a smile" be stressful? The moderating role of personal control for American and French employees. Journal of Applied Psychology, 90(5), 893-904. Available at: https://doi.org/10.1037/00219010.90.5.893.

Joseph, D. L., \& Newman, D. A. (2010). Emotional intelligence: An integrative meta-analysis and cascading model. Journal of Applied Psychology, 95(1), 54-78. Available at: https://doi.org/10.1037/a0017286.

Kellett, J. B., Humphrey, R. H., \& Sleeth, R. G. (2006). Empathy and the emergence of task and relations leaders. The Leadership Quarterly, 17(2), 146-162. Available at: https://doi.org/10.1016/j.leaqua.2005.12.003.

Law, K. S., Wong, C.-S., \& Song, L. J. (2004). The construct and criterion validity of emotional intelligence and its potential utility for management studies. Journal of Applied Psychology, 89(3), 483-496. Available at: https://doi.org/10.1037/002 1-9010.89.3.483. 
Masa'deh, R. (2016). The role of emotional intelligence in enhancing organizational effectiveness: The Case of information technology managers in Jordan. Int. J. Communications, Network and System Sciences, 9(1), 234-249.

Mayer, J. D., \& Salovey, P. (1990). Emotional intelligence, imagination, cognition, and personality. Cognition and Personality, 9(3), $185-211$.

Mayer, J. D., \& Salovey, P. (1997). What is emotional intelligence? Emotional development and emotional intelligence: Implications for Educators (pp. 3-31). New York: Basic Books.

Mayer, J. D., Salovey, P., \& Caruso, D. (2002). Mayer-salovey-caruso emotional intelligence test (MSCEIT). Version 2.0. Toronto, Canada: MultiHealth Systems.

Mayer, J. D., \& Cobb, C. D. (2000). Educational policy on emotional intelligence: Does it make sense? Educational Psychology Review, 12(2), 163-183.

Mayer, J. D., Salovey, P., Caruso, D. R., \& Sitarenios, G. (2001). Emotional intelligence as a standard intelligence. Emotion, 1(3), $232-242$.

Mayer, J. D., Caruso, D. R., \& Salovey, P. (1999). Emotional intelligence meets traditional standards for an intelligence. Intelligence, 27(4), 267-298.

Murphy, K. R. (1989). Is the relationship between cognitive ability and job performance stable over time? Human Performance, 2(3), 183-200.

Offermann, L. R., Bailey, J. R., Vasilopoulos, N. L., Seal, C., \& Sass, M. (2004). The relative contribution of emotional competence and cognitive ability to individual and team performance. Human Performance, 17(2), 219-243. Available at: https://doi.org/10.1207/s15327043hup1702_5.

Petrides, K. V., Pita, R., \& Kokkinaki, F. (2007). The location of trait emotional intelligence in personality factor space. British Journal of Psychology, 98(2), 273-289. Available at: https://doi.org/10.1348/000712606x120618.

Pugh, S. D. (2001). Service with a smile: Emotional contagion in the service encounter. Academy of Management Journal, 44(5), $1018-1027$.

Schmidt, F. L., \& Hunter, J. E. (1981). Employment testing: Old theories and new research findings. American Psychologist, $36(10)$, $1128-1137$.

Spencer, L. M. J., \& Spencer, S. M. (1993). Competence at work: Models for superior performance. New York: John Wiley and Sons.

Steiner, C. (1984). Emotional literacy. Transactional Analysis Journal, 14(3), 162-173.

Sternberg, R. (1997). Successful Intelligence. New York: Plume.

Sy, T., Tram, S., \& O'hara, L. A. (2006). Relation of employee and manager emotional intelligence to job satisfaction and performance. Journal of Vocational Behavior, 68(3), 461-473. Available at: https://doi.org/10.1016/j.jvb.2005.10.003.

Ugoani, J., Amu, C., \& Kalu, E. (2015). Dimensions of emotional intelligence and transformational leadership: A correlation analysis. Independent Journal of Management \& Production, 6(2), 563-583.

Van Rooy, D. L., \& Viswesvaran, C. (2004). Emotional intelligence: A meta-analytic investigation of predictive validity and nomological net. Journal of Vocational Behavior, 65(1), $71-95$.

Wasielewski, P. L. (1985). The emotional basis of charisma. Symbolic Interaction, 8(2), 207-222. 